\title{
Chapter 13 \\ Understanding the Health Impacts and Risks of Exposure to Radiation
}

\author{
Taylor A. Choi, Sylvain V. Costes and Rebecca J. Abergel
}

\begin{abstract}
In this chapter, the biological effects of exposure to radiation are summarized and explained from the perspective of the Fukushima Daiichi accident. First, a series of fundamental concepts in radiation biology are addressed to define the different types and sources of ionizing radiation, and resulting paths of human exposure. The health effects prompted by exposure to radiation are then broadly categorized and correlated with the nature of exposure and its extent. Finally, those concepts are revisited to assess the potential health impacts and risks endured by the workers and general population affected by the uncontrolled release of radiation around the Fukushima area. In the wake of the 2011 accident, a surge of public concern over the safety of nuclear energy and potential health risks from radiation exposure has re-surfaced. To evaluate, understand, and mitigate those health risks, it is essential that scientific data be meticulously gathered, rigorously analyzed, and accurately communicated. Taking a systematic knowledge-based approach to accurately capture the risks of exposure to radiation will not only alleviate mass confusion, but also help public health officials and emergency responders better prepare and implement logistics, should another such unfortunate event take place. The topics discussed in this chapter are intended to provide basic tools for understanding how health effects and risks related to radiation exposure are evaluated.
\end{abstract}

Keywords Health effects - Radiation exposure - Contamination • Radionuclides

T.A. Choi $\cdot$ R.J. Abergel $(\square)$

Chemical Sciences Division, Lawrence Berkeley National Laboratory,

One Cyclotron Road, Berkeley, CA 94720, USA

e-mail: rjabergel@lbl.gov

S.V. Costes

Life Sciences Division, Lawrence Berkeley National Laboratory,

One Cyclotron Road, Berkeley, CA 94720, USA

(C) The Author(s) 2015

J. Ahn et al. (eds.), Reflections on the Fukushima Daiichi Nuclear Accident,

DOI 10.1007/978-3-319-12090-4_13 


\subsection{Introduction}

In March 2011, the Great East Japan Earthquake and Tsunami led to the Fukushima Daiichi Nuclear Power Plant (NPP) accident, which released a large amount of radioactive material into the environment. While ionizing radiation is a ubiquitous and natural phenomenon that occurs all around us [1], a major release of radioactivity to the environment is always of concern, as it could result in acute and long-term health effects in surrounding populations.

Naturally occurring sources of radiation are broadly categorized into cosmic, terrestrial (e.g., earth's crust, soil, and construction material), and internal radiation $[1,2]$. In addition, people are routinely exposed to man-made radiation from nuclear medical diagnostics (e.g., X-ray and Computerized Tomography scans) and treatment procedures, nuclear power plants, commercial flying, and even smoking [2]. However, scientific evidence from past events have demonstrated that any major uncontrolled release of radiation could be harmful and warrants immediate response to assess and minimize public health risks.

About two years after the Fukushima Daiichi NPP disaster, the World Health Organization (WHO) released a global report on 'Health Risk Assessment from the nuclear accident after the 2011 Great East Japan Earthquake and Tsunami based on preliminary dose estimation' [3]. Conducted by an independent team of international experts on radiation risk, this comprehensive study concluded that, for the general population inside and outside of Japan, the predicted risks were low and no observable increases in cancer rates above baseline were anticipated.

The WHO report was the first large analysis of the global health effects due to radiation exposure after the Fukushima Daiichi NPP accident [3]. As additional data are gathered and further monitoring and analysis of radiation levels are performed, a more accurate picture of the health risks will be drawn. This chapter is intended to briefly summarize important concepts in radiation biology that are the basis for understanding how health effects and risks related to radiation exposure are evaluated. The second part of this chapter then focuses on the health impacts resulting from the radiation release around the Fukushima Daiichi NPP. Rather than be an in-depth review of lowdose radiation, this chapter is intended to provide background information on low-dose ionizing radiation and integrate the information in order to better understand the effects of low-dose ionizing radiation from the perspective of the Fukushima Daiichi accident. For further reading on low-dose radiation, we refer readers to Appendix B.

\subsection{Fundamental Concepts}

\subsubsection{Defining and Measuring Ionizing Radiation}

Ionizing radiation transports sufficient energy to convert a neutral atom to a charged ion, which may result in harmful changes to the irradiated body. Common types of ionizing radiations include alpha $(\alpha)$ radiation, beta $(\beta)$ radiation, gamma $(\gamma)$ rays, 


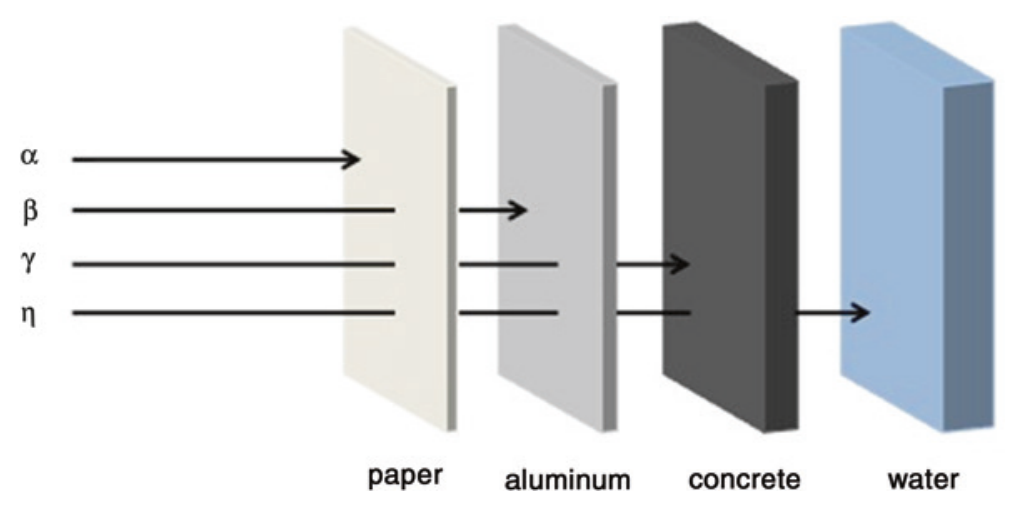

Fig. 13.1 Illustration of different types of ionizing radiation and energies

and neutrons [1, 2], as illustrated in Fig. 13.1. Alpha radiation consists of a heavy, positively charged helium nucleus. Alpha particles are short range, meaning they can be readily stopped with a sheet of paper, a few decimeters of thin air, or human skin [1]. Alpha particles pose a health risk if taken into the body through inhalation, ingestion, or wounds [4]. Beta radiation involves electrons and is more penetrating than $\alpha$ particles. Most $\beta$ particles will pass through a sheet of paper but can be stopped with a thicker object, such as a sheet of aluminum or a pane of glass. Beta particles may also be a health risk if taken into the body. Gamma rays and X rays are penetrating electromagnetic radiation and carry no electrical charge. These non-particle rays easily pass through paper, glass, and the human body but can be stopped by concrete or lead $[1,5]$. Neutrons are uncharged, indirectly ionizing radiation that can give rise to $\alpha, \beta, \gamma$, and X-rays. They can be stopped by thick masses of concrete or water $[5,6]$.

Activity is a measure of the amount of radiation a source produces, while dose is a measure of the amount of radiation that reaches an irradiated matter [1]. The quantity of radioactivity is measured in becquerel (Bq), the unit of radioactivity defined by the International System of Units (SI) [2]. The curie (Ci), a non-SI unit of radioactivity, is sometimes used and is defined in terms of disintegrations per unit of time $\left(1 \mu \mathrm{Ci}\right.$ is equivalent to $2.2 \times 10^{6}$ disintegrations $/ \mathrm{min}$; $1 \mu \mathrm{Ci}=37 \mathrm{kBq}$ ). One $\mathrm{Bq}$ corresponds to one atom decaying per second. But exactly how much is a Bq? At how many $\mathrm{Bq}$ will a genetic mutation or cancer occur? Becquerel is a very small unit. The human body contains between 5,000 and $10,000 \mathrm{~Bq}$ of natural radioactive elements (mainly potassium- $40,{ }^{40} \mathrm{~K}$ ). Smoke detectors typically contain about 30,000 Bq of americium-241 $\left({ }^{241} \mathrm{Am}\right)$. Patients are often exposed to radioactivity in $\mathrm{kBq}-\mathrm{MBq}$ quantities during a medical diagnostics procedure and MBq-GBq quantities in therapeutics. The physical dose of radiation does not necessarily correlate to the degree of biological damage. For the same physical amount of radiation energy, alpha particles are biologically more harmful than gamma rays. In addition, tissues and organs exhibit different levels of radiosensitivity [1]. 
Table 13.1 SI and conventional units used in radiation biology

\begin{tabular}{|c|c|c|}
\hline & SI unit & Conventional unit \\
\hline \multirow[t]{2}{*}{ Radioactivity } & Becquerel (Bq) & Curie $(\mathrm{Ci})$ \\
\hline & \multicolumn{2}{|c|}{$\begin{array}{l}1 \mathrm{~Bq}=1 \text { disintegration per second } \\
1 \mathrm{Ci}=3.7 \times 10^{10} \text { disintegrations per } \\
\text { second }=37 \mathrm{GBq}\end{array}$} \\
\hline \multirow[t]{2}{*}{ Absorbed dose } & Gray (Gy) & $\mathrm{rad}$ \\
\hline & \multicolumn{2}{|c|}{$1 \mathrm{~Gy}=1 \mathrm{~J} / \mathrm{kg}=100 \mathrm{rad}$} \\
\hline \multirow[t]{2}{*}{ Effective dose } & Sievert (Sv) & rem \\
\hline & \multicolumn{2}{|l|}{$1 \mathrm{~Sv}=100 \mathrm{rem}$} \\
\hline \multirow[t]{2}{*}{ Linear energy transfer } & Newton $(\mathrm{N})$ & $\mathrm{keV} / \mu \mathrm{m}$ \\
\hline & \multicolumn{2}{|c|}{$\begin{array}{l}1 \mathrm{~N}=1 \mathrm{~J} / \mathrm{m} \\
1 \mathrm{keV} / \mu \mathrm{m}=1.6 \times 10^{-13} \mathrm{~N}\end{array}$} \\
\hline
\end{tabular}

The absorbed dose is the mean quantity of radiation energy deposited per mass of tissue or organ $(\mathrm{J} / \mathrm{kg}$ or Gy) [1, 2]. Initially defined in terms of rads by the International Commission on Radiation Units and Measurement (ICRU) in 1953, it has been replaced by the SI unit gray (Gy) [6]. Table 13.1 summarizes commonly used SI and conventional units.

Another important unit for ionizing radiation is the Linear Energy Transfer (LET). This parameter reflects the energy loss of charged particles per unit path length and is also referred in physics as the stopping power. LET can be described by the Bethe equation [7] and has a typical unit of $\mathrm{keV} / \mu \mathrm{m}$. LET makes the most sense for energetic ions found in cosmic radiation, which are referred to as highLET radiation or HZE (High $\mathrm{Z}$ and Energy ions). These ions are relativistic, and with very high positive charge, deposit as much as hundreds to thousands of $\mathrm{keV} / \mu \mathrm{m}$ via Coulomb interaction with surrounding electrons in the tissues they traverse [8]. In contrast, $\mathrm{X}$-rays, $\gamma$-rays and electrons are often referred to as low-LET radiation $(<10 \mathrm{keV} / \mu \mathrm{m})$, which only makes sense for electrons, as photons do not interact via Coulomb interaction but via Pair production, Compton scattering, or photoelectric effects. Low-LET photons typically refer to the low-LET electrons produced via the interaction of photons with tissues.

The severity of biological damage varies with the type of radiation. It is interesting to note that very little difference is observed below $10 \mathrm{keV} / \mu \mathrm{m}$, making ionizing radiation in the low-LET range a good reference for biological effects [8]. This has led radiation biologists and health physicists to define the effective (or biological) dose, measured in Sieverts (Sv), as the low-LET dose required to induce the same health effect as observed for a higher LET radiation $[1,9]$. Therefore, one Sv corresponds to one gray (Gy) or Joule/kg (J/kg). The effective dose is calculated by multiplying the absorbed dose of a specific radiation type in Gy by a radiation weighting factor, referred to as the relative biological effectiveness (RBE) [2, 10]. For example, the RBE for high-LET $\alpha$ emitters is around 20 against 1 for $\gamma$ rays, $X$ rays, and $\beta$ radiation [10]. Neutrons may have RBE of 5-20 depending on the energy and the endpoint. One $\mathrm{Sv}$ is a fairly high dose; an acute exposure of $0.5-1.0 \mathrm{~Sv}$ can cause acute radiation diseases. Cancer patients may be exposed to this level of radiation during radiotherapy [1]. 


\subsubsection{A Perspective on Natural Versus Man-Made Radiation}

The International Commission on Radiological Protection (ICRP) recommends an effective dose of $10 \mathrm{mSv}$ as the annual dose reference level for humans [11]. The United Nations Scientific Committee on the Effects of Atomic Radiation (UNSCEAR) estimates that the global population receives an average annual effective dose of $\sim 3.1 \mathrm{mSv}$ ( $2.4 \mathrm{mSv}$ and $\sim 0.7 \mathrm{mSv}$ from natural background and anthropogenic radiation, respectively) [12]. Terrestrial radiation sources include primordial radionuclides such as uranium $\left({ }^{238} \mathrm{U}\right)$ and thorium $\left({ }^{232} \mathrm{Th}\right)$ [2]. Indwelling radon comprises about half of the overall average annual dose. Medical procedures (i.e., X-rays, CT scans) account for the majority of anthropogenic sources of radiation [13]. For occupational workers, the recommended annual dose limit to the whole body and extremities is 20 and $500 \mathrm{mSv}$, respectively [12]. While the dose rate from natural radionuclides in the body is independent of geographical location, the level of exposure to cosmic and terrestrial radiation can vary significantly depending on altitude [1]. For example, at 3,000 m above sea level, people receive five times more radiation dose than people at sea level [2].

\subsubsection{Distinguishing External from Internal Exposure}

Exposure to radiation may be classified into three categories: (i) body exposure due to the proximity of a radiation source, (ii) external contamination, and (iii) internal contamination.

All types of ionizing radiation may result in total or partial body exposure, with the severity of irradiation dependent upon the type and energy of the radiation. In contrast, external or internal contamination occurs when radionuclides or fission products settle on or penetrate human bodies via three primary routes [4, 14]:

- inhalation of airborne radionuclide particles

- ingestion of contaminated water and foodstuffs

- direct exposure via open skin from contaminated surface deposition

Numerous factors influence the potential health effects after contamination with radionuclides $[3,4,10]$ :

- chemical nature of the radionuclide or radiation source

- the physicochemical characteristics of the radionuclide (radiological and biological half-life, particle size, chemical composition, solubility, etc.)

- the behavior of radionuclides after radionuclide intake into the body

- radionuclide dose and dose rate

- type of radiation

- radiation dose-response relationships for individual tissue following radiation uptake

- sensitivity of different tissues and organs

- age and health of the contaminated individual 
The chemical nature of the ingested radionuclide strongly dictates the extent of absorption in the GI tract. For example, iodine and cesium are almost completely absorbed, whereas less than $0.1 \%$ of plutonium and americium are absorbed. The distribution of incorporated radionuclides in the body also depends on the solubility of the particles. In general, absorption is greater after ingestion of soluble inorganic forms than after ingestion of inorganic forms of an element. For example, ingestion of ${ }^{239} \mathrm{Pu}$ as nitrate or citrate results in at least one order of magnitude greater absorption than as oxide particles. Similarly, intake of soluble radioactive materials via inhalation or open wounds results in greater absorption and deposition in other tissues. In addition, the pattern of radioactivity distribution (i.e., uptake and retention) throughout irradiated tissues may influence the degree of damage. This is particularly true for alpha emitters because of localized deposition of energy and their greater RBE compared with that of beta or gamma emitters. For example, $\alpha$-emitting ${ }^{239} \mathrm{Pu}$ localizes in tissues and causes fibrosis, ulceration, loss of tissue function, and even death [10]. Ingestion of insoluble forms of radionuclides with $\alpha$ or $\beta$ emission may be largely confined to the gastrointestinal tract, whereas radionuclides with $\gamma$ emission may irradiate neighboring tissues. After 7 half-lives, less than $1 \%$ of the original activity remains and after 10 half-lives, less than $0.1 \%$ of the original activity remains [4].

\subsection{Categorizing the Health Effects of Radiation}

\subsubsection{Direct Versus Indirect Effects}

DNA damage or damage of other essential cellular components can occur by one of two mechanisms: direct or indirect effects. Different cell systems have different levels of sensitivity to radiation-actively replicating cells such as white blood cells are more sensitive to radiation than dormant cells or cells that do not regenerate as rapidly [15]. Mature cells in the brain, nerves and muscles are the slowest to regenerate and are thus least radiosensitive [4, 15].

Direct effects of ionizing radiation essentially affect DNA, which is directly ionized leading to a lesion. Indirect effects of ionization involve radiolytic decomposition of water in a cell. Water makes up most of a cell's volume and has a high probability of being affected when a cell is irradiated. Upon irradiation, water molecules break, producing hydrogen and hydroxide free radicals. These radicals can recombine to form water, or, in the presence of molecular oxygen, may form hydrogen peroxide, which will oxidize a variety of targets, including the DNA [15]. Typically for low LET, $60 \%$ of DNA double strand breaks (DSB) are due to indirect effect. In contrast, high-LET radiation induces the majority of DSBs via the direct effect.

\subsubsection{Acute Versus Chronic Effects}

Biological effects of radiation are broadly categorized into acute or chronic effects. Acute effects arise as a result of exposure to high doses of radiation over a 
short period of time, whereas chronic effects are a result of exposure to low doses of radiation over an extended period of time. High dose radiation exposure can lead to death. Depending on the dose and dose rate, along with other contributing factors, irradiated cells can repair minor damages, reproduce despite incurred damages, mutate and pass down mutations, or die. Furthermore, people respond differently to the same radiation dose. The health and age of the individuals at the time of exposure seem to impact the response outcome [15].

Damages to skin are more likely to occur with exposure to low energy gamma, $\mathrm{X}$-ray, or beta radiation. Acute high doses of X-ray or gamma irradiation can lead to impaired organ function or cell death. Erythema and blistering occur after acute doses of $>3$ and $>12$ Gy, respectively. Similarly, epilation (hair loss) can occur after acute doses of about 5 Gy. Depending on the dose (typically $>4$ Gy), sterility in males can be temporary or permanent. In females, sterility is usually permanent. Cataracts can occur at about 2 Gy [15]. At doses greater than $50 \mathrm{~Gy}$, severe necrosis, impaired vision, ataxia, and/or coma may occur [12].

Whole-body dose exposure of 3-5 Gy is sufficient to damage bone marrow and may subsequently lead to death within 2 months. At 5-15 Gy, the GI and respiratory tracts are compromised and death can occur in 2-3 weeks. A whole-body dose of above 15 Gy can cause damage to the nervous system and result in death within 1-2 days. In contrast, low dose levels of ionizing radiation exposure typically do not cause immediate observable effects for individuals [15]. The biological impacts of low dose of ionizing radiation are still being debated and have been an active field of research in the world for many decades. The general consensus from epidemiological studies involving A-bomb survivors [16] is that cancer risk increases with dose for acute doses larger than $100 \mathrm{mSv}$. The A-bomb survivor data are, however, limited by the following: dose was delivered acutely and dose rate and exposure duration are other important factors to predict cancer incidence. However, if radiation dose is received over an extended period of time at low dose rates, stochastic effects such as cancer may ensue [4].

\subsubsection{Deterministic Versus Stochastic Effects}

Deterministic or non-stochastic effects are health effects in which severity varies with dose; they are believed to occur only after certain radiation dose thresholds are exceeded [3]. Examples of deterministic effects include erythema, cataracts, organ atrophy, fibrosis, and sterility. Deterministic effects have an individually variable dose threshold, and are complex to deduce a dose-response relationship [17]. Stochastic effects, on the other hand, are probabilistic adverse health effects of ionizing radiation that increase with increasing dose, without a threshold [3, 17]. Radiation risks from high dose rate or acute effects are primarily deterministic effects and are typically reported in Gy. Low dose rate or chronic effects are primarily stochastic effects, in particular, cancer $[3,4]$. According to the WHO report, deterministic effects are not expected to occur in the general population, inside and outside of Japan, due to low radiation dose levels resulting from the Fukushima accident [3]. 


\subsubsection{Homogeneous Versus Heterogeneous Irradiation}

ICRP reviewed a limited number of studies comparing the biological effects of homogeneous and heterogeneous irradiation of tissues, and concluded the effect of uniformity of irradiation when contaminated with internal radionuclides through inhalation or ingestion was inconclusive [10].

The available information for irradiation of the lung, skin or liver, however, indicates that, in general, non-uniform alpha irradiation from internalized radioactive particles is no more hazardous, and may be less hazardous, than if the same activity were uniformly distributed $[10,18]$. In one animal study, Chinese hamsters were burdened with different particle sizes of ${ }^{239} \mathrm{Pu}$ citrate or ${ }^{239} \mathrm{PuO}_{2}$ in order to compare the effects of particle size on local radiation dose and dose rate to the surrounding cells in inducing chromosome aberrations. The study suggested a correlation between biological response and the distribution of dose: more uniformly distributed ${ }^{239} \mathrm{Pu}$ citrate produced more chromosome aberration, suggesting that, in some cases, energy deposition or saturation at the cellular level is impacted by heterogeneity of plutonium distribution [19].

\subsection{Correlating Radiation Exposure with Health Effects}

As stated above, biological effects resulting from radiation exposure are highly correlated with received radiation dose and dose rate. Acute Radiation Syndrome (ARS), or radiation sickness, is the result of whole body exposure to very high levels of radiation, usually over a short period of time. While people who suffered from ARS include survivors of the atomic bombs and first responders after the Chernobyl NPP event in 1986, populations affected by radiation release and contamination schemes similar to those seen after the Fukushima accident are much more likely to experience chronic low dose effects. The following sections therefore focus on the health effects of exposure to low dose ionizing radiation and internal contamination with radionuclides.

\subsubsection{Low Dose Ionizing Radiation}

A low dose of ionizing radiation is generally defined as an acute exposure of $<100 \mathrm{mGy}$ (mSv) [20]. In the context of biology, the term "low dose" is the lowest dose of energy deposited in a single cell that results in cellular changes [21]. Interestingly, internalized radioactive materials deposited at low dose rates are not uniformly distributed at all levels of biological organization. The mechanisms of action for the biological responses induced by low doses of ionizing radiation are different from those induced by high doses. Responses estimated using linear extrapolation of high dose should be prudently interpreted since this method 
overestimates the real risk associated with these low dose and dose rate exposures. By and large, non-uniform distribution of low doses is less hazardous than single, acute whole-body exposures, as shown in DNA repair processes [11, 22].

Challenges lie in linking direct risk estimates for exposures at low doses. Radiation is a weak carcinogen and its effects are too small to quantify, as we are all exposed to natural background radiation at around this low level, which may mask any significant effects. Are internally deposited low dose radioactive materials more harmful than external exposures? There is no conclusive scientific evidence that shows fundamental differences between external and internal sources of radiation, or between artificial and natural radionuclides in their capacity to cause such damage. It is important to consider the location of target cells within tissues when considering doses from short-range internal emitters (e.g., alpha particles, low energy electrons) [23].

\subsubsection{Linear-No-Threshold Model}

There are conflicting schools of thought in the radiation community on stochastic health effects associated with exposures to low doses of ionizing radiation [20]. Current risk estimates and most radiation protection standards are based on the 'linear-no-threshold' (LNT) model [21]. The LNT hypothesis does not reflect the actual risk in the low-dose region, but provides a useful tool to conservatively control exposure [11]. According to this model, the effect of ionizing radiation is directly proportional to the dose, and even the smallest dose of radiation is associated with a small increase in cancer risk to humans without a threshold [24, 25]. The Biological Effects of Ionizing Radiation (BEIR) committee of the National Academy of Sciences (NAS) published a report in 2006 concluding that the available biological and biophysical data support the LNT risk model [24, 25].

In the same year, UNSCEAR issued a report citing that while the LNT hypothesis holds validity in radiation protection at low doses and low dose rates, it does not reflect the actual risk in the low dose region [12, 20, 21, 24]. In a subsequent 2012 study, UNSCEAR also concluded that there is no consensus on the impact of radiation exposure, particularly at low doses [26]. ICRP reached a conclusion similar to that of UNSCEAR and stated in their Recommendations guidance that current evidence does not support a universal threshold dose level, although a lowdose threshold is likely applicable for radiation-related cancers in certain tissue [5, 24, 27].

The French Academy of Sciences challenged the validity of the LNT model for assessing health risks at low doses [28]. The LNT model posits that carcinogenic risks remain constant in all biological reactions, regardless of dose or dose rate. The group pointed out that epidemiological studies did not show a significant increase of cancer incidence in humans for doses $\lesssim 100 \mathrm{mSv}$. In addition, the LNT model fails to take into consideration the various biological mechanisms cells demonstrate when they are irradiated by ionizing radiation. The group concluded that the universal 
approach of the LNT model greatly simplifies the dose-effect relationships and may result in an overestimation of health risk at low doses since biological mechanisms and responses are different at low doses versus high doses [29, 30].

Some researchers subscribe to the once discredited hormesis concept, a hypothesis that receiving low ionizing radiation in doses just above the natural background level may induce beneficial biological responses [17]. The proponents of this hypothesis explain that a number of compensatory and reparatory mechanisms (e.g., stimulation of the immune response and DNA repair, and activation of apoptosis that eliminates damaged cells that would otherwise become cancerous) are stimulated in response to small doses of ionizing radiation [17, 31].

Stochastic effects are more likely to occur after acute exposure to internalized radionuclides than deterministic effects. At absorbed doses of $\sim 1 \mathrm{~Gy}$, deterministic effects may occur, including pneumonitis, erythema, vomiting and diarrhea, bone marrow failure, and cataracts. Some of these symptoms appear several hours after an acute absorbed dose, whereas others may take weeks or longer [4].

\subsubsection{Chronic Exposure to Low Dose Radiation}

The main concern associated with chronic exposure to irradiation at low doses is the induction of cancer [10]. Using the LNT model (see above), the risk of cancer is estimated to increase by $10 \%$ for chronic health effects above $100 \mathrm{mSv}$ [14]. However, several large cohort studies of nuclear medical technicians and nuclear industry workers suggest a slight increase in cancer risk at exposures below $100 \mathrm{mSv}$. Estimating adverse health effects, such as cancer risks of chronic lowlevel radiation exposure is complicated by other variables, such as diet, lifestyle, genetics, and overall health [32].

Is there a threshold below which radiation has no adverse effect? Some researchers believe that natural background radiation can be a carcinogenic factor. Others are convinced that small doses of radiation (natural or anthropogenic) are not harmful [33]. Still others, albeit a small community of researchers and health experts, prescribe to the hormesis model [32]. Because we all receive doses $>1 \mathrm{mSv}$ from our natural surroundings, correlating adverse biological responses to low radiation doses is difficult. Models associated with the different hypotheses are illustrated in Fig. 13.2.

\subsubsection{Minimizing and Treating Exposure to Radiation}

The first response to radiation exposure should be to treat acute radiation syndrome. Treatment of ARS focuses on reducing infections, maintaining hydration, and treating injuries and burns. Causes of death are often attributed to bone marrow destruction, which is why some patients may benefit from bone marrow recovery treatments. It is not possible to reverse acute exposure to radiation; 


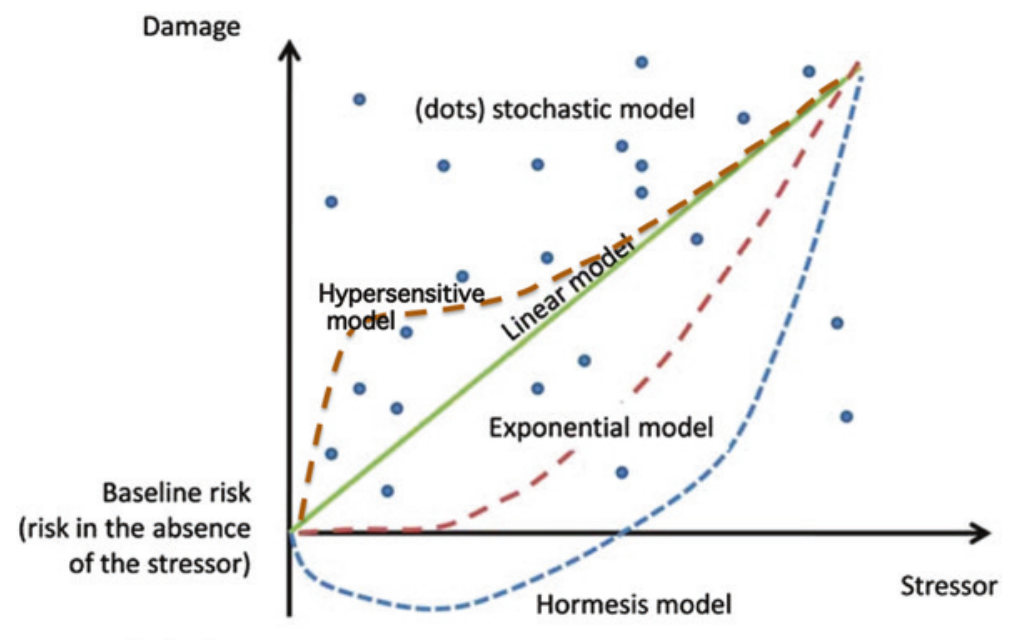

\section{Protection}

Fig. 13.2 Models discussed for evaluating the health effects of exposure to low-dose ionizing radiation. The baseline risk represents doses accumulated in excess of background natural sources (Adapted with permission from Biological effects of low-dose radiation: of harm and hormesis by Gori and Münzel, 2012, Eur. Heart J. 33:293)

however, it is important to minimize exposure in chronic exposure and internal contamination cases. Sources of radiation should be distanced or removed when possible, in order to reduce the radiation dose.

Currently available treatments vary as a function of the intake pathway, the level of contamination (mass and activity), the chemical and biological speciation of the radioisotope, as well as the intervention time after the incident. For contamination by inhalation, which primarily results from internalization of aerosols that display different chemical solubilities, treatment may include lung washing. For contamination by ingestion, treatments include gastric dressing, precipitation, and purging. For wound contamination, several treatments have been used including washing, surgical excision, and dressings with additional specific chelating gels.

Table 13.2 List of recommended treatments for representative radionuclides, adapted from [4]

\begin{tabular}{l|l}
\hline Radionuclide & Recommended treatment \\
\hline Americium & DTPA Chelation \\
\hline Cesium & Prussian Blue \\
\hline Iodine & Postassium iodide \\
\hline Iron & $\begin{array}{l}\text { Deferoxamine or EDTA } \\
\text { Chelation }\end{array}$ \\
\hline Potassium & Diuretics \\
\hline Plutonium & DTPA Chelation \\
\hline Radium & Strontium therapy \\
\hline Strontium & Strontium therapy \\
\hline Yttrium & DTPA Chelation \\
\hline
\end{tabular}


In all cases, where radioactive materials are deposited internally, a blocking or decorporation agent should be administered to prevent the settling or promote the removal of radioactive materials from tissues and organs. A comprehensive list or radionuclides and the corresponding treatment can be found in the NCRP Report [4]. Table 13.2 lists a few representative radionuclides and their corresponding recommended treatment.

\subsection{The Fukushima Daiichi Nuclear Power Plant Accident}

A series of natural disasters in Japan on March 11, 2011 resulted in an unanticipated extent of damage to infrastructure, including the meltdown of three of the six nuclear reactors at the Fukushima Daiichi NPP, and the subsequent release and deposition of radioactive materials into the environment $[6,9]$. This uncontrolled release of radiation triggered a surge of public concern over the potential health risks of radiation exposure. Readers are referred to Chap. 3 for an in-depth analysis of the mechanisms of environmental contamination and to Chap. 4 for a description of decontamination strategies and waste management issues.

Immediately after the accident on March 11, 2011, the Japanese government ordered residents within a $3 \mathrm{~km}$ radius around the Fukushima Daiichi NPP to evacuate. As the seriousness of the accident became more apparent, evacuation areas were gradually expanded. On March 12, 2011, after the 1st explosion at the nuclear reactor No. 1, areas within a $20 \mathrm{~km}$ radius from the NPP were evacuated. On March 15, residents living in the 20-30 km range from the NPP were instructed to stay indoors. By the end of 2011, additional restrictions took effect, which impacted specific areas northwest of the NPP, corresponding to the migration pattern of radioactive particles after the accident. These restricted areas were rearranged into three zones according to the annual cumulative dose, with a confirmed annual integral radiation dose of less than $20 \mathrm{mSv}$ in Zone $1,20 \mathrm{mSv}$ or more in Zone 2, and $50 \mathrm{mSv}$ or more in Zone 3. The status of these zones, as of April 1, 2014, is depicted in Fig. 13.3.

\subsubsection{Estimating the Exposure to Ionizing Radiation and Subsequent Impact}

The general population in Japan receives an annual natural background radiation dose of about $2.1 \mathrm{mSv}$. This is comparable to the global natural background average of $\sim 2.4 \mathrm{mSv}$ (range of 1-13 $\mathrm{mSv}$ depending on geographical location and radon exposure) $[34,35]$. Table 13.3 summarizes the annual doses received by the Japanese population as a function of source, in comparison with average doses estimated worldwide.

The effective dose over a lifetime from naturally occurring sources of radiation in Japan is about $170 \mathrm{mSv}$, which is higher than the estimated effective dose 

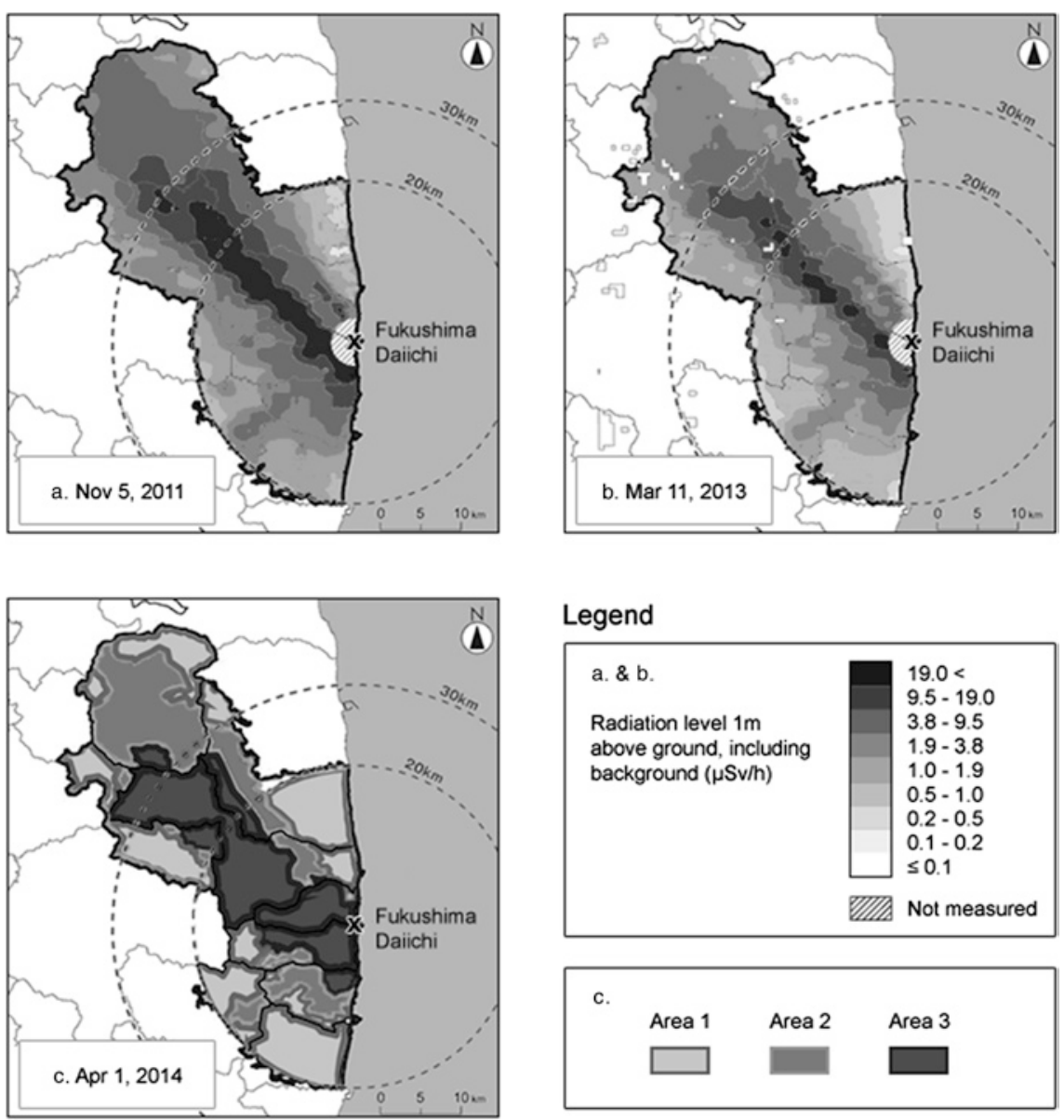

\section{Legend}

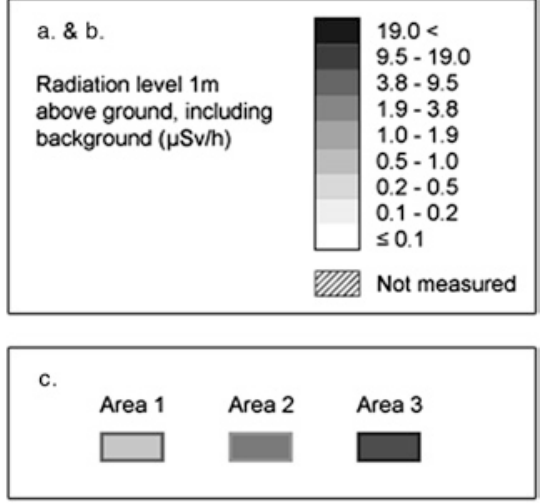

Fig. 13.3 Maps of radiation levels (a November 5, 2011 and b March 11, 2013), and evacuation areas (c April 1, 2014). Figure created using data available on the website of the Japanese Ministry of Economy, Trade and Industry

Table 13.3 Annual radiation exposure estimates in Japan and Worldwide [12, 36]

\begin{tabular}{l|l|l}
\hline Source & Annual dose in Japan & $\begin{array}{l}\text { Annual dose in the } \\
\text { World }\end{array}$ \\
\hline Natural background & 2.1 & 2.4 \\
\hline Diagnostic radiology & 2.20 & 0.62 \\
\hline Nuclear medicine & 0.03 & 0.03 \\
\hline Fallout & 0.01 & 0.01 \\
\hline Others (nuclear plant, aircraft, etc.) & 0.01 & 0.01 \\
\hline Total & 4.35 & 3.1 \\
\hline
\end{tabular}


from the Fukushima Daiichi NPP accident for an average person living in the Fukushima Prefecture. The annual and lifetime doses to the thyroid from natural sources of radiation are about 1 and $80 \mathrm{mGy}$, respectively [34]. A post-incident health survey suggested that the received dose for nearly all the evacuees was low, with a maximum acute dose of $\sim 25 \mathrm{mSv}$ [10]. The mean annual radiation dose in 2012 attributed to the accident was $0.89-2.51 \mathrm{mSv}$. The mean dose rate attributed to the accident in 2022 is projected to be $0.31-0.87 \mathrm{mSv}$. In addition, annual internal exposure to fallout is estimated to be $0.0025 \mathrm{mSv}$ [35].

An acute radiation dose of $100 \mathrm{mSv}$ has been linked to an increase in the chance of developing cancer by a factor of 1.05 , which is unlikely to be epidemiologically detectable $[32,35,37]$. The annual limit on the occupational effective dose for Japanese workers is $20 \mathrm{mSv} /$ year and $100 \mathrm{mSv}$ over 5 years [14, 38]. The emergency dose exposure was raised from 100 to $250 \mathrm{mSv} / \mathrm{year}$, the established limit in emergency situations, in response to the gravity of the accident, as suggested by the ICRP $[14,27]$. Acute exposures to radiation at these levels are not expected to result in adverse health effects. The average lifetime cancer risk for a worker from a whole-body dose of $250 \mathrm{mSv}$ will be 1-2 \%, depending on the dose rate [27], which is quite low compared with a background lifetime risk of 20-25\% [38]. As of March 2012, 408 workers received doses above the established annual limit of $50 \mathrm{mSv}$. Among them, 6 workers received doses greater than $250 \mathrm{mSv}$ and 2 other workers received doses above $600 \mathrm{mSv}$ [38, 39]. In addition, two workers received significant skin doses of $\sim 2-3 \mathrm{~Sv}$. Yet, no acute radiation sickness or acute radiation effects have been reported thus far. Nonetheless, these workers are continuously monitored [14, 38-40].

In its 2012 report, the WHO committee stated that observable increases in cancer risk above natural variation in baseline rate are unlikely in the Fukushima prefecture and the geographical areas most affected by radiation. For the residents in the most affected location of the Fukushima prefecture, the estimated relative increases in lifetime risks over baseline rates for specific cancers are [3]:

- Leukemia_ 7\% in males exposed as infants

- breast cancer- $6 \%$ in females exposed as infants

- all solid cancers- 4 \% in females exposed as infants

- thyroid cancer-up to $\sim 70 \%$ in females exposed as infants (the lifetime absolute baseline risk of thyroid cancer in females is $0.75 \%$, which is increased to $1.25 \%)$

For residents in the second most contaminated location, the radiation dose for the first year is estimated to be $\sim 12 \mathrm{mSv}$. The additional lifetime cancer risk for these residents is estimated to be approximately half of that in the highest dose location. It should be kept in mind that these estimates were calculated based on some assumptions. For example, it was assumed that all people in the Fukushima prefecture consumed food in only the Fukushima prefecture. The estimate also assumed that people in the most affected areas outside the $20-\mathrm{km}$ radius continued to live there for 4 months after the accident. Therefore, these risk estimates are more likely to be overestimates than underestimates [3]. 
So far, no one has died as a direct result of radiation exposure from the Fukushima Daiichi NPP, while some 18,500 fatalities have resulted from the earthquake and the subsequent tsunami. Cancer-related deaths as the consequence of the Fukushima accident are estimated to be statistically insignificant. In comparison, $0.1 \%$ of the 111,000 emergency workers at Chernobyl have so far developed leukemia, which cannot be ascribed entirely to the accident itself [41].

Estimating the biological effects of low doses is complex, and lifetime cancer risk varies according to several factors, mainly radiation dose, duration of exposure, age at the time of exposure, sex, general health, and cancer site. These factors can influence the uncertainty in projecting radiation risks, in particular risk assessment at low doses [3]. Biological functions do not have a uniform response, especially to low levels of radiation [32]. These factors were taken into consideration in data analysis for the Fukushima accident, and experts concluded that there is an increased cancer risk for certain subsets of the population in the most contaminated areas of the Fukushima Prefecture. However, no observable increases in cancer incidence are expected in other populations within the Fukushima prefecture [3]. Nonetheless, the health of these individuals will be monitored for an extended period of time. Delayed cancers due to chronic low dose radiation exposure will be challenging to isolate because of various environmental factors and personal lifestyles. In many areas of Japan, individual risk of cancer from natural background radiation will likely be greater than the risk from the Fukushima accident [42].

\subsubsection{Radionuclides Released from the Fukushima Daiichi Nuclear Power Plant}

Radionuclides released into the environment as a result of the nuclear accident were: iodine-131 $\left({ }^{131} \mathrm{I}\right)$, iodine-133 $\left({ }^{133} \mathrm{I}\right)$, cesium-134 $\left({ }^{134} \mathrm{Cs}\right)$, cesium-137 $\left({ }^{137} \mathrm{Cs}\right)$, and tellurium-132 $\left({ }^{132} \mathrm{Te}\right)$ [43]. Other radionuclides of concern included strontium $\left({ }^{90} \mathrm{Sr}\right)$, yttrium $\left({ }^{90} \mathrm{Y}\right)$, lanthanide fission products, and actinides, but none of these have been measured in any detectable quantities within or beyond the established evacuation zone [10]. Most releases of noble gases (i.e. ${ }^{133} \mathrm{Xe}$ ) would have occurred in the early days after the accident [3]. It is estimated that 160,88 , 18 , and $15 \mathrm{PBq}$ of ${ }^{131} \mathrm{I},{ }^{132} \mathrm{Te},{ }^{134} \mathrm{Cs}$, and ${ }^{137} \mathrm{Cs}$, respectively, were discharged from the Fukushima Daiichi NPP into the environment [43].

A primary health concern for internal exposure to ${ }^{131} \mathrm{I}$ is the potential development of thyroid cancer, since the thyroid gland is most sensitive to ${ }^{131}$ I [44]. Examples of deterministic health effects induced by inhalation of $\beta$-emitting ${ }^{131} \mathrm{I}$ include bone marrow depression (1-10 Gy), hypothyroidism (10-100 Gy), and ablation of the thyroid gland (100-100 Gy). Increased stochastic effects induced by the inhalation of ${ }^{131}$ I are estimated to be observed at an exposure 10-100 Sv [4]. Children are more susceptible than adults to risks of cancer from radiation [11]. For example, children receiving a $100 \mathrm{mSv}$ thyroid dose have a $0.3 \%$ increased risk of developing thyroid cancer [45]. ${ }^{131} \mathrm{I}$ has a half-life of only 8 days, meaning 
human exposure to an external source of this radionuclide is relatively short [41]. It is volatile and can be inhaled. It can also be ingested because it readily enters the food chain $\left({ }^{131} \mathrm{I}\right.$ deposits on the ground). Similar to stable iodine, ${ }^{131} \mathrm{I}$ is actively taken up by the thyroid gland. Once ${ }^{131} \mathrm{I}$ is taken up by the thyroid gland, a constant bombardment of surrounding tissue can overwhelm the repair mechanisms of cells and trigger cancer [3]. Tokonamii et al. calculated the median thyroid equivalent dose to 4.2 and $3.5 \mathrm{mSv}$ for children and adults, respectively [44].

Stable iodine tablets were distributed to Fukushima accident evacuees within a week after the accident. An oral dose of stable iodine blocks the uptake of ${ }^{131}$ I by the thyroid, although the timing of the intake of stable iodine relative to exposure is important to optimize the effect of this protective measure [38]. Nagataki reviewed the results of thyroid equivalent doses in the initial phase of the accident in the most affected areas of Fukushima prefecture and concluded that $96 \%$ of the children received $<10 \mathrm{mSv}$, with a maximum of $35 \mathrm{mSv}$, which is lower than the IAEA intervention level $(50 \mathrm{mSv})[46,47]$. It should be noted, however, that any increase in thyroid cancer cases may not be evident until several years following the incident (as was the case in the children and adolescent age groups in the Chernobyl region) [41].

${ }^{134} \mathrm{Cs}$ and ${ }^{137} \mathrm{Cs}$, with a half-life of 2.1 and 30.2 years, respectively, pose a longterm threat since they remain on the ground [48]. Examples of deterministic health effects induced by inhalation of $\beta-\gamma$ emitting ${ }^{137} \mathrm{Cs}$ include mild bone marrow depression and erythema (1-10 Gy), bone marrow failure, pneumonitis, and GI failure (10-1,000 Gy), with a very high risk of death above $100 \mathrm{~Gy}$. Increased stochastic effects induced by inhalation of ${ }^{137} \mathrm{Cs}$ is estimated to occur at a dose of $1 \mathrm{~Sv}$ [4].

Current recommended decorporation therapy in the event of cesium intake is oral administration of Prussian Blue. Overall, solubility of particles affects the biokinetics in the body. Soluble forms would be better absorbed into the blood and result in higher content in tissues. The system biokinetics of $\mathrm{Cs}$ is similar to that of $\mathrm{K}$, although $\mathrm{Cs}$ does not cross cell membranes as readily as $\mathrm{K}$ does. Inhaled or ingested, Cs is readily absorbed either from the GI tract or the lungs and is subsequently taken up by most tissues [10]. Upon reaching the systemic circulation, Cs distributes uniformly in the body, with a higher concentration in skeletal muscle than in most other tissues [4]. According to the Japanese Ministry of Health, Labor and Welfare, radioactive cesium in foods is less than $1 \%$ of $1 \mathrm{mSv} / \mathrm{year}$ as of April 2014, and that radiation levels in public water supplies are below allowable limits [49].

The third largest source of radioactivity released from the Fukushima Daiichi NPP is ${ }^{132} \mathrm{Te}$. This radionuclide has a half-life of 3.2 days and decays to ${ }^{132} \mathrm{I}$, which has a half-life of $2.3 \mathrm{~h}$, and then becomes ${ }^{132} \mathrm{Xe}$, which is a stable isotope. Hence, ${ }^{132} \mathrm{Te}$ is biologically relevant during the first few days after a nuclear accident [43].

\subsubsection{Health Effects and Consequences}

Taking into account uncertainties associated with the LNT model of human exposure at low doses, Ten Hoeve and Jacobson used the model to quantify long term health effects. They factored in ingestion exposure, inhalation exposure, and 
external exposure pathways of radioactive ${ }^{131} \mathrm{I},{ }^{137} \mathrm{Cs}$, and ${ }^{134} \mathrm{Cs}$ released from Fukushima. They estimated 130 mortalities and 180 morbidities related to cancer, chiefly in the most affected areas of Fukushima. These estimates do not account for the increased radiation risk for roughly 20,000 workers at the plant in the months following the accident [39].

Because most people were exposed to radiation doses that were just slightly above background, attributing carcinogenic effects to radiation exposure from the Fukushima accident is difficult $[32,50]$. This challenge is mainly due to the multitude of variables that should be taken into consideration, such as smoking, diet, geographical location, etc. Furthermore, cellular damage incurred by irradiation may not manifest until many years after exposure. Some researchers assert that even a well-implemented study will not yield statistically significant data on stochastic effects, such as cancer. It should also be noted that $40 \%$ of all Japanese develop cancer [32].

It is also important to consider the short- and long-term psychological effects following a devastating accident. The intangible nature of radiation exposure heightens the public's feelings of fear and vulnerability [51]. The Chernobyl disaster has illustrated that long-term psychological effects, including post-traumatic stress disorder, depression, anxiety, fear, and unexplained physical symptoms, may increase following a nuclear accident $[12,39,51]$.

\subsection{Conclusions}

In the wake of the Fukushima Daiichi accident, safety concerns regarding nuclear energy have re-emerged into the limelight. All energy technologies, however, carry a certain level of risk [11] and the world is increasingly relying on nuclear power for energy [39]. As of May 2014, 435 nuclear reactors are operating throughout the world and 72 new nuclear plants are under constructions [52]. One study shows that using nuclear power to generate electricity is a safe alternative to technologies such as burning coal [11].

While currently available data suggest that the health consequences in those outside the epicenter of the Fukushima accident may be minimal, it is too early to know what the long term health consequences of the Fukushima Daiichi accident will be [14]. As science continues to evolve and more data become available, researchers face unanticipated observations that may result in paradigm changes. It is essential that scientists make comprehensive use of data to effectively and accurately communicate to the public and policy makers so that the perception of radiation hazards and risks associated with exposure to low doses of radiation is accurately captured [11]. This will help alleviate mass confusion as well as help public health officials and emergency responders better prepare and implement logistics should another event such as the Fukushima Daiichi accident take place. Furthermore, such practice will aid in the advancement of nuclear safety.

Our understanding of the biological mechanisms of action of radiation at low doses has greatly improved. Health risks at very low doses can only be 
estimated by extrapolating the data of individuals exposed at much higher doses. Therein lie inherent uncertainties and challenges. It is possible that the current radiation risk for internally deposited radioactive material is underestimated or overestimated [23].

Three years after the Fukushima disaster, the situation has improved and many local residents have returned to their homes. Despite relatively low dose exposures and reassurance from public health experts and government officials, public perception may be that cancer cases in or around Fukushima are caused by the NPP accident. Questions will continue to linger about chronic effects of exposure to low levels of radiation, and this event will likely be the subject of many scientific and governmental reviews and debates for many years to come.

Acknowledgments The authors extend their special thanks to Dahlia An of the Chemical Sciences Division at the Lawrence Berkeley National Laboratory for her help improving the readability of this chapter and assistance with the figures.

\section{Appendix A: Glossary of Useful Terms}

Absorbed dose

Acute effects

Acute exposure

Acute radiation syndrome

\section{Alpha particle}

\section{Becquerel}

Beta particle

Chronic effects

\section{Decorporation agent}

\section{Deterministic (or stochastic) effects}

The mean quantity of radiation energy deposited per mass of tissue or organ, expressed in grays (Gy)

Adverse health effects that arise as a result of exposure to high doses of radiation over a short time (minutes to a few days)

Exposure to a low dose of ionizing radiation for a short period of time $(<24 \mathrm{~h})$

Radiation sickness as a result of whole-body exposure to very high levels of radiation, usually over a short period of time

A positively charged helium nucleus characterized by short range and low penetrating capability

The SI unit of radioactivity, equal to one disintegration per second

A charged particle (electron or positron) emitted from a nucleus during radioactive decay

Adverse health effects as a result of exposure to low doses of radiation over an extended period of time (years)

The therapeutic processes by which radioactive materials are mobilized from tissues and organs and caused to be excreted from the body

Health effects in which the severity varies with dose 


\section{Direct effect}

Dose

Effective (or biological) dose

Gamma ray

Half-life

\section{Health effects}

\section{Health risk}

Hormesis

Indirect effect

Ionizing radiation

Linear no-threshold model

\section{Neutron}

Radioactivity

\section{Radionuclide}

Relative biological effectiveness (RBE)

Sievert

Source

Stochastic effect
Ionization energy resulting in damage to essential cellular components

The quantity of radiation absorbed in a target

Absorbed dose to each organ, taking into account the relative biological effectiveness of different types of ionizing radiation

Uncharged, electromagnetic radiation emitted from a nucleus during radioactive decay

The time required for one-half of the atoms of a particular radioactive substance to decay to some other substance

Changes in the health status of an individual or population, identifiable by diagnostic or epidemiological methods

The probability of a health effect to occur in the event of an exposure to a hazard (e.g. radiation)

A hypothesis that receiving low ionizing radiation doses may induce beneficial biological responses Ionization energy resulting in radiolytic decomposition of water in a cell

Radiation capable of removing electrons from an atom

A risk model that assumes that the effect of ionizing radiation is directly proportional to the dose, without any threshold

Uncharged, indirectly ionizing radiation

The process by which radioactive atoms spontaneously releases energy in the form of alpha or beta particles or gamma rays

Radioactive species of an atom, characterized by an unstable nucleus

The ratio of the absorbed dose of ionizing reference radiation to the absorbed dose of a specified radiation

The SI unit of effective dose, equal to $1 \mathrm{~J} / \mathrm{kg}$ Anything that may cause radiation exposure Probabilistic adverse health effects of ionizing radiation that increases with increasing dose, without a threshold 


\section{Appendix B: Suggested Literature for In-Depth Reading of Topics Discussed in This Chapter}

15 July 2005 letter to The Honorable Dale E. Klein, Chairman, U.S. Nuclear Regulatory Commission titled "Report of the French Academy of Sciences, "The dose-effect relationship and estimating the carcinogenic effects of low doses of ionizing radiation." Washington, DC

Barcellos-Hoff, MH, Ravani SA (2000) Irradiated mammary gland stroma promotes the expression of tumorigenic potential by unirradiated epithelial cells. Cancer Res 60:1254-1260

Brenner, DJ, Sachs, RK (2006) Estimating radiation-induced cancer risks at very low doses: rationale for using a linear no-threshold approach, Radiat Environ Biophys, 44:253-256.

Burklakova, EB (2000) Low doses of radiation: are they dangerous? Nova Science Pub Inc, Huntington

Burklakova, EB (2013) The effects of low dose radiation: new aspects of radiobiological research prompted by the Chernobyl nuclear disaster. VSP, Leiden

Calabrese, EJ (1994) Biological effects of low level exposures dose-response relationships. CRC Press, Boca Raton

Cantone, MC, Hoeschen, C (2011) Radiation physics for nuclear medicine. Springer, Berlin

Choppin, G, Liljenzin, J-O, Rydbergy, J, Ekberg, C (2013) Radiochemistry and nuclear chemistry, Elsevier, Oxford

Eidus, LK (2002) Biological action of low doses of radiation: a novel view on the problem. Nova Science Pub, Ann Arbor

Klaunig, JE, Kamendulis, LM (2004) The role of oxidative stress in carcinogenesis, Annual review of pharmacology and toxicology, 44:239-267

Luckey, TD (1991) Radiation Hormesis. CRC Press, Boca Raton

Nygaard, OF, Sinclair, WK, Lett, JT (1992) Effects of low doses and low dose rate radiation Academic Press, San Diego, CA

Standton, R, Stinson, D (2009) Applied physics for radiation oncology, revised edition. Medical Physics Publishing, Madison

Wilson, 3rd, DM, Bohr, VA (2007) The mechanics of base excision repair, and its relationship to aging and disease, DNA repair, 6:544-559

Yamada, T, Mothersill, C, Michael, BD, Potten, CS (2000) Biological effects of low dose radiation: Proceedings of the international meeting on biological effects of low dose radiation. Cork, Ireland, 25-26 July 1999

Open Access This chapter is distributed under the terms of the Creative Commons Attribution Noncommercial License, which permits any noncommercial use, distribution, and reproduction in any medium, provided the original author(s) and source are credited. 


\section{References}

1. Valentin J (1994) Radiation: levels and doses in everyday life. Radioprotection 29(3, Suppl.):45-58

2. Raabe OG (2012) Ionizing radiation carcinogenesis. Current Topics in Ionizing Radiation Research. Nenoi M (ed) InTech Rijeka, Croatia

3. World Health Organization (2013) Health risk assessment from the nuclear accident after the 2011 Great East Japan Earthquake and Tsunami based on preliminary dose estimation. Switzerland

4. National Council on Radiation Protection and Measurements (2008) Management of persons contaminated with radionuclides. NCRP draft SC 4-1 report

5. International Atomic Energy Agency (2010) Radiation biology: a handbook for teachers and students

6. International Commission on Radiation Units and Measurements (2011) Report 86. Quantification and reporting of low-dose and other heterogeneous exposures

7. Bethe H, Ashkin J (1953) Experimental Nuclear Physics. Segré J (ed) Wiley, New York

8. International Commission on Radiation Units and Measurements (1970) Linear energy transfer. ICRU Report 16. Washington D.C. Accessed 03 Jul 2014

9. Food and Drug Administration (2009) Radiation quantities and units. http://www.fda.gov/ Radiation-EmittingProducts/RadiationEmittingProductsandProcedures/MedicalImaging/Med icalX-Rays/ucm115335.htm Accessed 03 Jul 2014

10. Harrison JD, Stather JW (1996) The assessment of doses and effects from intakes of radioactive particles. J Anat 189 (Pt 3):521-530

11. Brooks AL (2013) Thirty-sixth Lauriston S. Taylor lecture on radiation protection and measurements-from the field to the laboratory and back: the what ifs, wows, and who cares of radiation biology. Health Phys 105(5):407-421

12. United Nations Scientific Committee on the Effects of Atomic Radiation (2006) Effects of ionizing radiation. UNSCEAR 2006 report to the general assembly with scientific annexes, Vol. 1

13. Watson SJ, Jones AL, Oatway WB, Hughes JS (2005) Ionising radiation exposure of the UK populations. HPA-RPD-001, HPA, Chilton

14. American Nuclear Society (2012) Fukushima Daiichi: ANS committee report

15. USNRC (2012) Biological effects of radiation. USNRC technical training center reactor concepts manual

16. Preston RJ, Ron E, Tokuoka S, Funamoto S, Nishi N, Soda M, Mabuchi K, Kodama K (2007) Solid cancer incidence in atomic bomb survivors: 1958-1998. Radiat Res 168:1-64

17. Gori T, Münzel T (2012) Biological effects of low-dose radiation: of harm and hormesis. Eur Heart J 33(3):292-295

18. International Commission on Radiological Protection (1991) The biological basis for dose limitation in the skin. ICRP Publication 59. Oxford: Pergamom Press

19. Brooks AL, Retherford JC, McClellan RO (1974) Effect of 239PuO2 particle number and size on the frequency and distribution of chromosome aberrations in the liver of the Chinese hamster. Radiat Res 59(3):693-709

20. Morgan WF, Bair WJ (2013) Issues in low dose radiation biology: the controversy continues. A perspective. Radiat Res 179(5):501-510

21. Mitchel REJ, River C (2002) Radiation biology of low doses. ATW Internationale Zeitschrift für Kernenergie 47:28-30

22. Neumaier T, Swenson J, Pham C, Polyzos A, Lo AT, Yang P, Dyball J, Asaithamby A, Chen DJ, Bissell MJ, et al. (2012) Evidence for formation of DNA repair centers and doseresponse nonlinearity in human cells. Proc Natl Acad Sci U S A 109(2):443-448

23. Mobbs SF, Muirhead CR, Harrison JD (2010) Risks from ionising radiation. Health Protection Agency, Radiation Protection Division HPA-RPD

24. Dauer LT, Brooks AL, Hoel DG, Morgan WF, Stram D, Tran P (2010) Review and evaluation of updated research on the health effects associated with low-dose ionising radiation. Radiat Prot Dosimetry 140(2):103-136 
25. National Academy of Sciences (2006) Health risks from exposure to low levels of ionizing radiation: BEIR VII, Phase 2. Committee to assess health risks from exposure to low levels of ionizing radiation, board of radiation effects, Research division on earth and life studies, National Research Council of the National Academies

26. United Nations Scientific Committee on the Effects of Atomic Radiation (2012) Biological mechanisms of radiation actions at low doses

27. International Commission on Radiological Protection (2007) The 2007 recommendations of the international commission on radiological protection. ICRP Publication 103. Ann. ICRP 37. Oxford: Pergamom Press

28. Tubiana M, Feinendegen LE, Yang C, Kaminski JM (2009) The linear no-threshold relationship is inconsistent with radiation biologic and experimental data. Radiology 251(1):13-22

29. Tubiana M (2005) Dose-effect relationship and estimation of the carcinogenic effects of low doses of ionizing radiation: the joint report of the Academie des Sciences (Paris) and of the Academie Nationale de Medecine. Int J Radiat Oncol Biol Phys 63(2):317-319

30. Tubiana M, Aurengo A, Averbeck D, Masse R (2006) Recent reports on the effect of low doses of ionizing radiation and its dose-effect relationship. Radiat Environ Biophys 44(4):245-251

31. Kaiser J (2003) Hormesis. Sipping from a poisoned chalice. Science 302(5644):376-379

32. Normile D (2011) Tohoku-Oki earthquake. Fukushima revives the low-dose debate. Science 332(6032):908-910

33. Normile D (2013) Japan disaster. Cooling a hot zone. Science 339(6123):1028-1029

34. United Nations Scientific Committee on the Effects of Atomic Radiation (2013) Sources, effects and risks of ionizing radiation USCEAR 2013 report to the general assembly, scientific annex A. New York: United Nations

35. Harada KH, Niisoe T, Imanaka M, Takahashi T, Amako K, Fujii Y, Kanameishi M, Ohse K, Nakai Y, Nishikawa T, et al. (2014) Radiation dose rates now and in the future for residents neighboring restricted areas of the Fukushima Daiichi nuclear power plant. Proc Natl Acad Sci U S A 111(10):E914-923

36. Tsushima Y, Taketomi-Takahashi A, Takei H, Otake H, Endo K (2010) Radiation exposure from CT examinations in Japan. BMC Med Imaging 10:24

37. Brumfiel G (2013) Fukushima: Fallout of fear. Nature 493(7432):290-293

38. Wakeford R (2011) And now, Fukushima. J Radiol Prot 31(2):167-176

39. Ten Hoeve JE, Jacobson MZ (2012) Worldwide health effects of the Fukushima Daiichi nuclear accident. Energy Environ Sci doi:101039/c2ee22019a

40. Gonzalez AJ, Akashi M, Boice JD, Jr., Chino M, Homma T, Ishigure N, Kai M, Kusumi S, Lee JK, Menzel HG, et al. (2013) Radiological protection issues arising during and after the Fukushima nuclear reactor accident. J Radiol Prot 33(3):497-571

41. Rhodes CJ (2014) The Fukushima Daiichi nuclear accident. Science Progress 97(Pt 1):72-86

42. Beyea J, Lyman E, von Hippel F (2013) Accounting for long-term doses in "worldwide health effects of the Fukushima Daiichi nuclear accident”. Energy Environ Sci 6:1042-1045

43. Tagami K, Uchida S, Ishii N, Zheng J (2013) Estimation of Te-132 distribution in Fukushima prefecture at the early stage of the Fukushima Daiichi nuclear power plant reactor failures. Environ Sci Technol 47(10):5007-5012

44. Tokonami S, Hosoda M, Akiba S, Sorimachi A, Kashiwakura I, Balonov M (2012) Thyroid doses for evacuees from the Fukushima nuclear accident. Sci Rep 2:507

45. von Hippel FN (2011) The radiological and psychological consequences of the Fukushima Daiichi accident. Bulletin of the Atomic Scientists 67:27-36

46. Nagataki S, Takamura N, Kamiya K, Akashi M (2013) Measurements of individual radiation doses in residents living around the Fukushima nuclear power plant. Radiat Res 180(5):439-447

47. International Atomic Energy Agency (2011) Report of Japanese government to IAEA ministerial conference on nuclear safety - accident at TEPCO's Fukushima nuclear power station. http://www.iaea.org/newscenter/focus/fukushima/japan-report Accessed 03 Jul 2014 
48. Tanaka S (2012) Accident at the Fukushima Dai-ichi nuclear power stations of TEPCO—outline \& lessons learned. Proc Jpn Acad Ser B Phys Biol Sci 88(9):471-484

49. Japanese Ministry of Health, Labor and Welfare (2011) Information on the Great East Japan Earthquake. http://www.mhlw.go.jp/english/topics/2011eq/index_food.html Accessed 24 July 2014

50. Cuttler JM (2013) Commentary on Fukushima and beneficial effects of low radiation. Dose Response 11:432-443

51. Bromet EJ (2014) Emotional consequences of nuclear power plant disasters. Health Phys 106(2):206-210

52. European Nuclear Society (2014) http://www.euronuclear.org/info/encylcopedia/n/nuclearpower-plant-world-wide.htm Accessed 03 Jul 2014 